\title{
Numerical simulation of sea breeze characteristics observed at tropical coastal site, Kalpakkam
}

\author{
P JAMIMA $^{1}$ and J LAKSHMINARASIMHAN ${ }^{2}$ \\ ${ }^{1}$ Research Associate, Dept. of Applied Mechanics, I.I.T., Madras 600036. \\ e-mail: jamima_p@yahoo.com \\ ${ }^{2}$ Professor, Dept. of Applied Mechanics, I.I.T., Madras 600036. \\ e-mail: jln_apm_iitm@hotmail.com
}

\begin{abstract}
Sea breeze characteristics around Kalpakkam tropical coastal site are studied using an Advanced Regional Prediction System (ARPS) mesoscale model, which is non-hydrostatic, compressible atmospheric prediction model following the terrain coordinate system. Various options such as surface physics, atmospheric radiation physics, Coriolis force, microphysics, cumulus parameterization and 1.5 level TKE closure scheme for diffusion are included in the model.

A joint meteorological field experiment was carried out by IITM-Pune and IGCAR at Kalpakkam by deploying state-of-the-art sensors and tether balloon systems for observing the height profiles of meteorological parameters. The data obtained from the field experiment are used here to compare the results from numerical simulations. From the simulated results, it is seen that duration of the sea breeze is 6 hours which agrees well with the observations. The height of the Thermal Internal Boundary Layer (TIBL) is also simulated from the vertical profiles of potential temperature. Simulated wind speed and wind directions are compared with the $50 \mathrm{~m}$ tower data and potential temperature profiles are compared with the kytoon data. Results are in good agreement with the observed values except during night time wherein a small difference is seen in the wind speed.
\end{abstract}

\section{Introduction}

Land and sea breezes are mostly observed mesoscale phenomena, which play an important role in coastal areas where industries are located and a large population resides. Many have discussed the importance of the study of sea breeze for problems such as air pollution transport, location and initiation of convection, aviation safety, gliding and sailing, and forest fire forecasting (Simpson 1995). Hence, it is important to understand the characteristics of sea breeze and structure of the thermal internal boundary layer.

Several researchers have studied the characteristics of sea breeze experimentally (Zambakas 1973; Ogawa et al 1986; Osamu et al 1994; Melas et al 1995) and numerically (Mahrer and Pielke 1977; Gross 1986; Arritt 1987; Xian and Pielke
1991; Klara Finkele 1998; Batchvarova and Gryning 1998; Cai and Steyn 2000; Liu et al 2001) by considering different effects responsible for the development of sea breeze and their impact on air pollution problems. A theoretical approach is given by Neumann and Mahrer (1971) to study the physical process responsible for the sea breeze development. Large-scale geostropic winds will have a significant impact on the development and the evolution of sea breeze. In earlier studies, Estoque (1962) used his two-dimensional numerical model to study the effects of large-scale flow on the development of sea breeze circulation. Bechtold et al (1991) used a two-dimensional mesoscale model to study the influence of large-scale winds on sea breeze and inland-breeze type circulations over flat terrain. It is found from their study that the intensity of sea breeze is at its maximum when prop-

Keywords. Sea breeze; thermal internal boundary layer; numerical modeling.

Proc. Indian Acad. Sci. (Earth Planet. Sci.), 113, No. 2, June 2004, pp. 197-209

(C) Printed in India. 
agation speed of the sea breeze front is cancelled by the background wind speed and turbulent mixing. Dynamics of land and sea breeze circulation in Santa Barbara were numerically studied by Novitsky et al (1992) using a two-dimensional numerical model.

Calculated wind profiles were compared with the measured data, which showed greater discrepancy for upper parts of the profiles, where errors in estimating geostropic conditions or synoptic-scale pressure variations are most evident. Carissimo et al (1996) used a three-dimensional, non-hydrostatic MECURE model to show that a mesoscale model with its physical parameterizations is able to reproduce a local phenomenon like the sea breeze by using a large scale forcing, simpler than nested techniques. The time evolution of simulated surface wind is in global agreement with the available observations whereas a difference in wind direction is seen as compared to the measurements made in two stations called Dafni and Liosia. A tropical sea breeze circulation over Cleveland Bay is simulated by Ma (1997) using a two-dimensional mesoscale model. The effects of local terrain, an island and large-scale wind on the sea-land breeze circulation are investigated and results are compared with the experimental data. He showed that the intensity of the simulated circulation was weaker than the real situation. However, it is suggested that only a three-dimensional model can hope to produce better agreement between the simulated results and observed data. Flow dynamics under moderate to large-scale winds were simulated by Melas et al (1998a) in Athens basin using a three-dimensional, hydrostatic higher-order turbulence closure model. The experimental data from MEDCAPHOT-TRACE is used to compare the simulated results. They observed that discrepancies are mainly due to uncertainty in estimating the surface temperature change with topography height. Nevertheless, the model does not include rural-urban temperature contrast. The same model and experimental data were used by Melas et al (1998b) to study the anatomy of sea breeze circulation in Athens under weak large-scale ambient winds. Sea breeze patterns were simulated well except with some differences in small-scale fluctuations near surface winds, found in observations but are smoothened in the simulated results. A twodimensional mesoscale model with 1.5 turbulent closure scheme, is developed by Thara et al (1999) for providing wind field for air pollution calculations. Meteorological data available from Oresund experiment was used to validate the model, which showed an over-prediction of the wind and temperature in the surface layer. The observed discrepancies were explained as due to non-inclusion of long wave radiation divergence, the use of flux pro- file relationships parameterized for homogeneous terrain, neglect of three-dimensional effects and hydrostatic assumptions. From all these studies, some discrepancies are always observed in most of the models when compared with field data. It is of course known that simulation of exact scenario of the real atmosphere is not possible.

Kalpakkam is a tropical coastal site with plain terrain and linear coastline where temperature of the land is quite high. Sea breeze is frequently observed in this region mainly due to difference in land and sea temperature and large-scale geostrophic winds. Though tropics have higher temperature than mid-latitudes, the difference between land and sea surface temperature is not more than $10^{\circ} \mathrm{C}$. This temperature difference is also higher in the tropics than higher altitudes. For example, in Chennai around mid-summer, the maximum temperature over land is $42^{\circ} \mathrm{C}$ and sea surface temperature is $27^{\circ} \mathrm{C}$ approximately. In these situations, the sea breeze will develop even opposing the geostrophic wind. Another reason is also because of weak Coriolis force which makes the steering of the wind also weak permitting the breeze to propagate as deep inland as possible. Few studies have been made with the help of field experiments but not numerically (CABLE-98, Thara et al 2002) to study the sea breeze characteristics around Kalpakkam. Hence, in the present paper, characteristics of sea breeze such as vertical and horizontal extent, duration, onset of sea breeze and thermal internal boundary layer structure were numerically predicted and validated with the observed data.

The main aim of the study is to see how best the model will simulate sea breeze characteristics under tropical conditions. ARPS model is chosen in this study as it incorporates most of the atmospheric dynamics and physics like the models which were mentioned above and if found suitable, it can be used for pollution dispersion simulation studies. Nevertheless, efforts continue towards further understanding of the shortcomings of the models and improving the models. The present study is yet another contribution in this direction.

\section{Model description, initialization and field experiment}

Advanced Regional Prediction System (ARPS), (Xue et al 2000; 2001) is a storm and mesoscale model developed by the Centre for Analysis and Prediction of Storms (CAPS), Oklahoma University. The model is a non-hydrostatic, compressible atmospheric prediction model in a terrain following coordinate with equal spacing in $x$ and $y$ directions and the grid stretching in the vertical direction. It 
is used for scales ranging from a few meters to hundreds of kilometers. The model can be run in $1 \mathrm{D}$, $2 \mathrm{D}$ and $3 \mathrm{D}$ modes.

The ARPS model solves prognostic equations for $u, v, w$, the $x, y$, and $z$ components of velocity, the perturbation potential temperature $\theta^{\prime}$, and perturbation pressure $P^{\prime}$, sub-grid scale turbulent kinetic energy and the six categories of water variables such as water vapor, cloud water, rain water, cloud ice, snow and hail. Detailed description of the model and governing equations are shown in the ARPS user's guide (Xue et al 1995). The various options used in the model are shown in table 1 below.

In the present study, the model was initialized using single sounding data at 6:00 hrs IST and at surface level data from field experiment is used for initialization. The number of grid points or nodes in $x, y$, and $z$ directions are 35,4 and 20 respectively and spacing between the grid $\mathrm{d} x$ and $\mathrm{d} y$ is given as $2000 \mathrm{~m}$. Horizontally $40 \mathrm{~km}$ from the coast is initialized as land and $30 \mathrm{~km}$ after the coastline as sea. In the first step the model was run in coarse grid with horizontal grid resolution of $5 \mathrm{~km}$ and also with $100 \mathrm{~km}$ land surface from the coast. But the simulated horizontal sea breeze extent was not more than $40 \mathrm{~km}$ as there was high synoptic wind opposing the sea breeze on the chosen day. So, the study is confined to $40 \mathrm{~km}$ for the computational ease. Sounding file shows that winds are southwesterly at lower levels and westerly at higher levels with jet at about $1 \mathrm{~km}$. The model was tested for Kalpakkam soil conditions (Jamima et al 2001) and skin temperature of the land and ocean were initialized as $297 \mathrm{~K}$ and $300 \mathrm{~K}$ respectively with $25 \%$ surface soil moisture taken from the observations of field experiment and buoy data. The model is run for 24 hours in its two-dimensional form. The horizontal and vertical grid positions of $x$ and $z$ co-ordinates used in the model are given below:
Table 1. Various options used in the ARPS model.

\begin{tabular}{|c|c|}
\hline Options & Description \\
\hline Initialization & External sounding \\
\hline $\begin{array}{l}\text { Vertical grid } \\
\text { stretching }\end{array}$ & Hyperbolic tangent function \\
\hline Buoyancy terms & Second order \\
\hline $\begin{array}{l}\text { Momentum and } \\
\text { scalar advection }\end{array}$ & Fourth order \\
\hline $\begin{array}{l}\text { Boundary conditions } \\
\text { west \& east } \\
\text { north \& south } \\
\text { top \& bottom }\end{array}$ & $\begin{array}{l}\text { Radiation } \\
\text { periodic } \\
\text { rigid }\end{array}$ \\
\hline Coriolis force & Yes \\
\hline Turbulence & $\begin{array}{l}\text { 1.5 TKE mixing } \\
\text { (Sun and Chang 1986) }\end{array}$ \\
\hline Micro physics & $\begin{array}{l}\text { Kessler warm rain with Kain \& } \\
\text { Fritsch convective cumulus } \\
\text { parameterization }\end{array}$ \\
\hline $\begin{array}{l}\text { Atmospheric } \\
\text { radiation }\end{array}$ & Yes \\
\hline Surface physics & Yes \\
\hline
\end{tabular}

The main objective of the field experiment is to collect the extensive data for the study of boundary layer dynamics focusing on TIBL characteristics under sea breeze conditions and dispersion characteristics around Kalpakkam coastal site. The site is located at the eastern coast of southern Indian peninsula at $12^{\circ} 34^{\prime} 28^{\prime \prime} \mathrm{N}$ latitude and $80^{\circ} 10^{\prime} 20^{\prime \prime} \mathrm{E}$ longitudes, $80 \mathrm{~km}$ south of Chennai City as shown in figure 1. The terrain is plain and elevated about

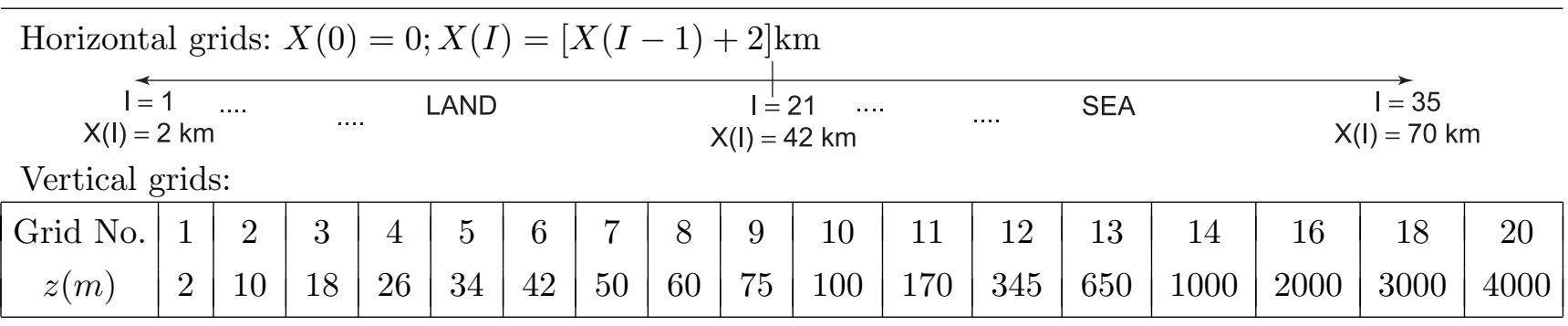

\subsection{Field experiment}

A series of field experiments, (CABLE-2001 Report; Sivaramakrishnan and Venkatesan 2002) at Kalpakkam, were conducted during summer monsoon along with the scientists of IITM-Pune and Andhra University from June 19th to July 6th, 2001 near Kalpakkam.
$1 \mathrm{~m}$ above MSL. The coastline is linear and runs along SSW-NNE. Vegetation in the study area consists of cultivation with tall buildings and trees with sandy clay soil.

The experimental site has more vegetated land than near the coast. The experiments were carried out near Anupuram and IGCAR new main gate, which are distant nearly $5.5 \mathrm{~km}$ and $1 \mathrm{~km}$ 


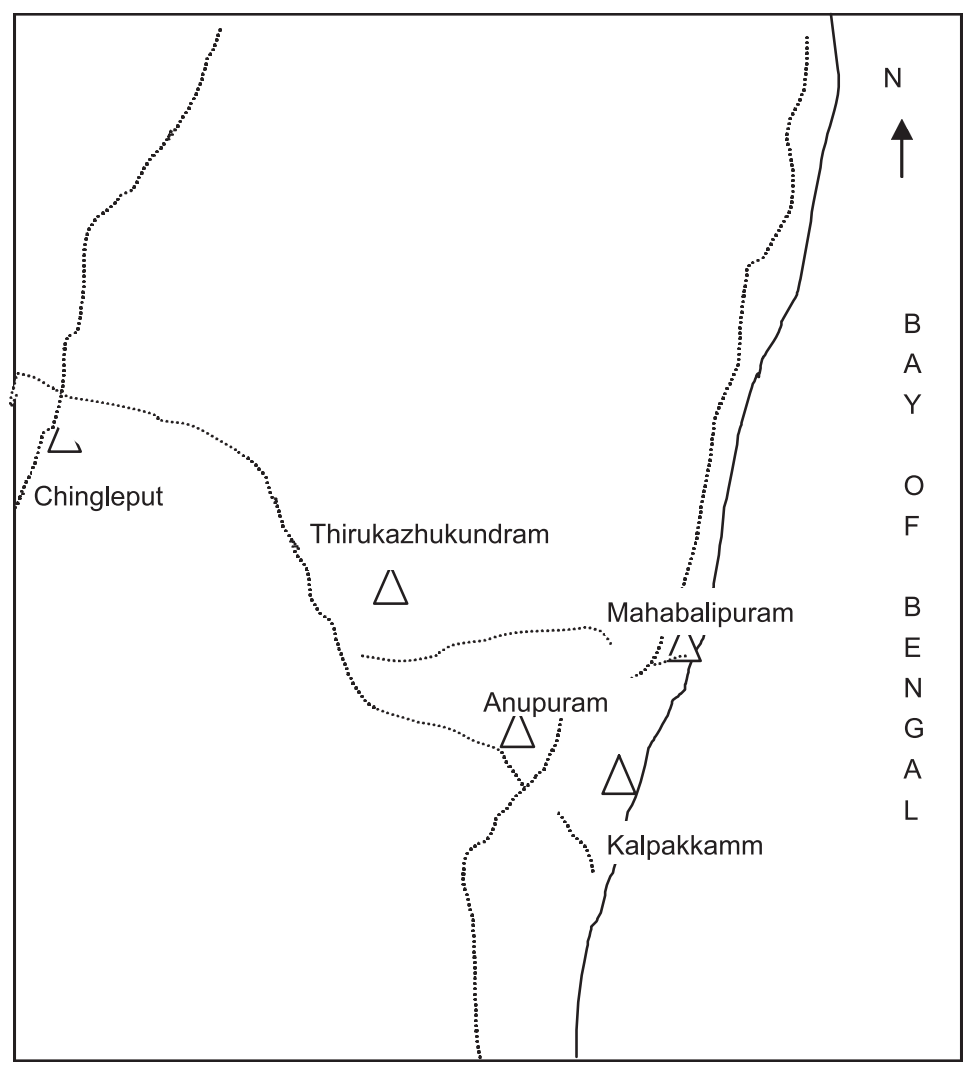

Figure 1. A sketch (not to scale) showing the field site Anupuram and Kalpakkam.

respectively from the coast. The experimental facilities include meteorological tower, sonic anemometer, tethered balloon and radiation measurements. Vertical profiles of meteorological parameters were collected using kytoon observations, and wind speed and direction were measured continuously at four different levels i.e., $10 \mathrm{~m}, 17 \mathrm{~m}, 29 \mathrm{~m}$ and $50 \mathrm{~m}$ respectively. Incoming short wave and long wave radiation, out going short wave and long wave radiation and net radiation were also measured using solar radiometers at $2 \mathrm{~m}$ above the ground level. Though there were rains some time, there was a suitable atmosphere with cumulus clouds for collecting the data on the chosen day. Synoptic data from IMD, Chennai was also taken during this period, which includes surface data, upper air data and vertical profiles of wind and temperature.

\section{Result and discussion}

Characteristics of the sea breeze and internal boundary layer circulation near Kalpakkam are numerically studied using ARPS model and compared with the observed values. Model was initialized using single sounding data taken from Indian Meteorological Department, Meenam- bakkam which is nearly $10 \mathrm{~km}$ inland from the coast at morning 05:30 hrs. Initial land and sea temperature are initialized as $297 \mathrm{~K}$ and $300 \mathrm{~K}$ respectively in the two layer soil model of ARPS and run for 24:00 hrs. The wind speed, direction and temperature profiles of the radiosonde observations used to initialize the model are shown in figure 2. The wind profile shows that winds are westerly and south westerly at lower levels at 05:30 hrs and 17:30 hrs respectively and easterly above $10 \mathrm{~km}$ at 05:30 hrs and 17:30 hrs. The Low Level Jet (LLJ) at 05:30 hrs is seen above $1 \mathrm{~km}$ $(\sim 13 \mathrm{~m} / \mathrm{sec})$ and at $10 \mathrm{~km}(\sim 14 \mathrm{~m} / \mathrm{sec})$ and at $17: 30 \mathrm{hrs}$ LLJ is seen above 3 to $4 \mathrm{~km}(13 \mathrm{~m} / \mathrm{sec})$ and above $10 \mathrm{~km}(19 \mathrm{~m} / \mathrm{sec})$ because of passing of summer monsoon trough. The potential temperature profile shows the strong stable stratification in troposphere up to $10 \mathrm{~km}$ during $05: 30 \mathrm{hrs}$ and 17:30 hrs.

The simulated results are discussed below.

\subsection{Structure of the wind}

The wind fields in the $x-z$ plane of the model at different hours i.e., 06:00, 15:00, 18:00 and 23:00 hrs are shown in figure 3 . They show the evolution of vertical circulation throughout the day. Morning at 


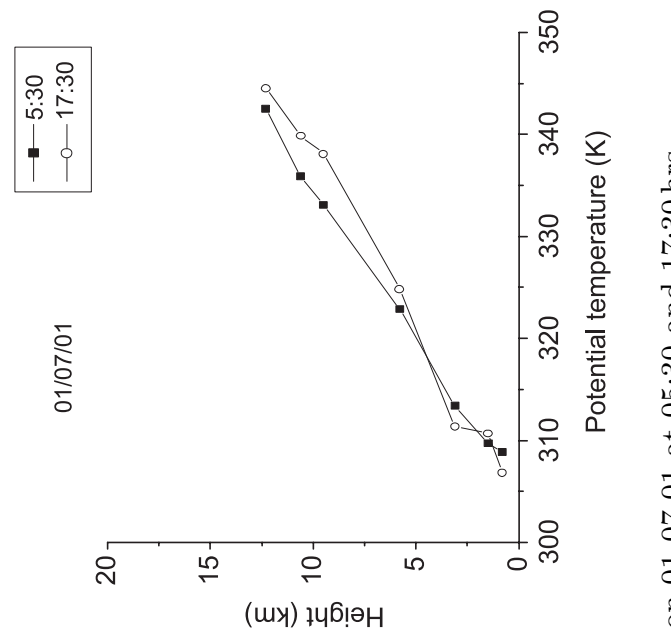

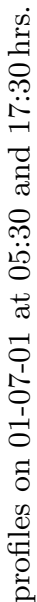

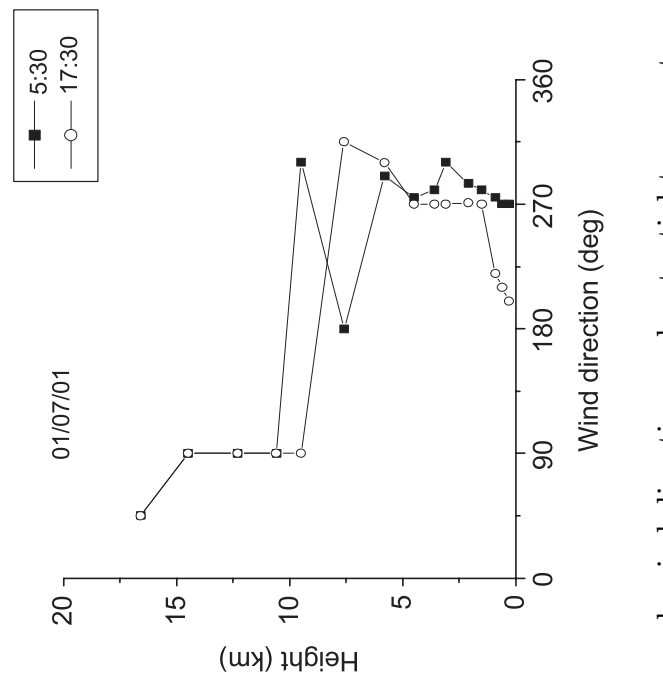

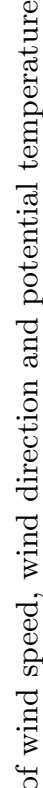

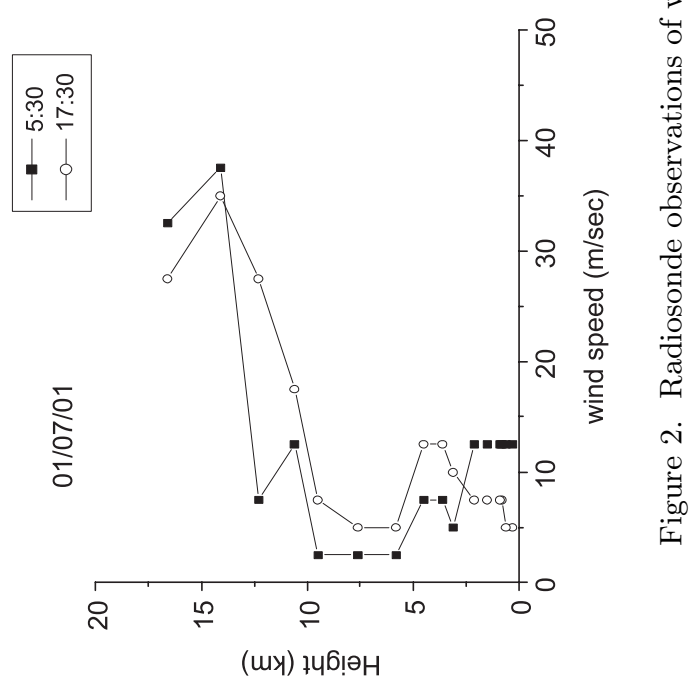




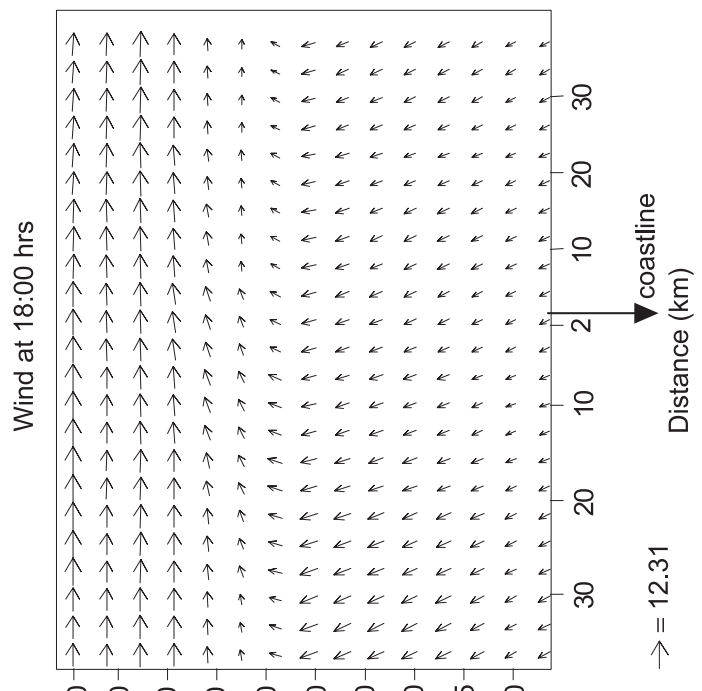

ㅇㅇㅇㅇㅇㅇㅇㅇㅇ 융응 안 우 (w) ұчढ़ाə̈

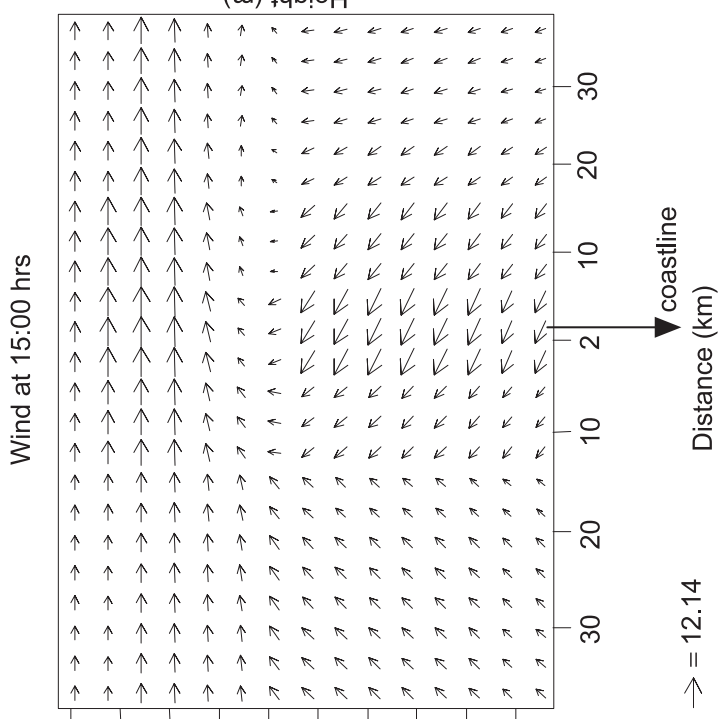

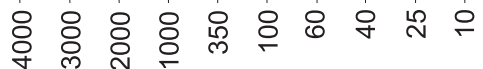

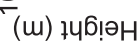
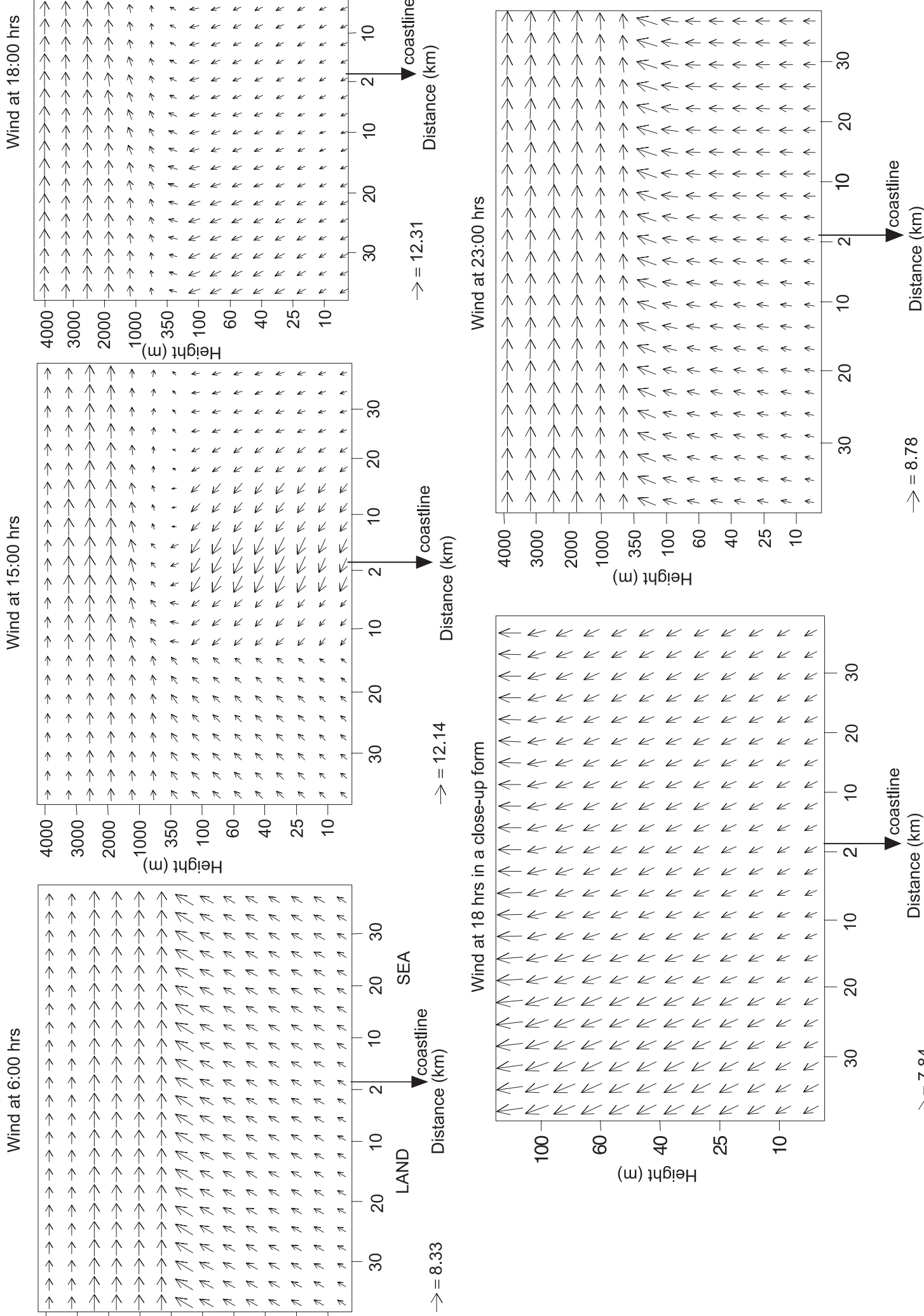

(u) $1466 !$ 하

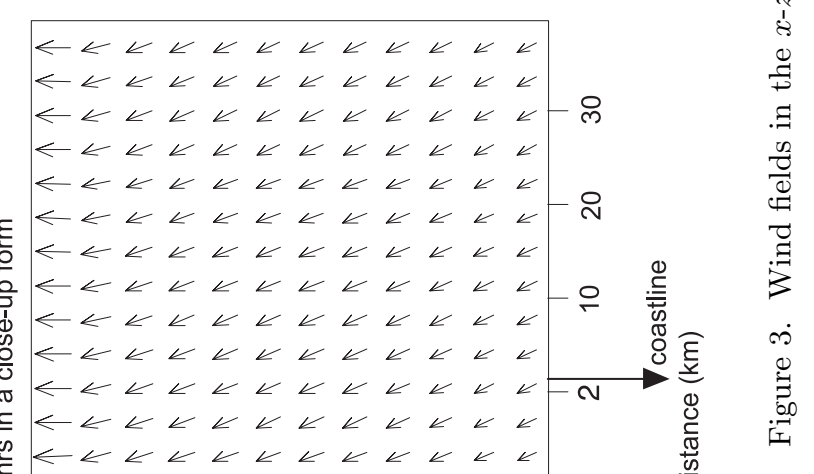

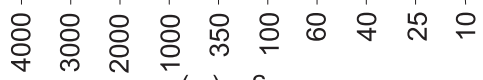

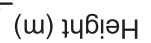




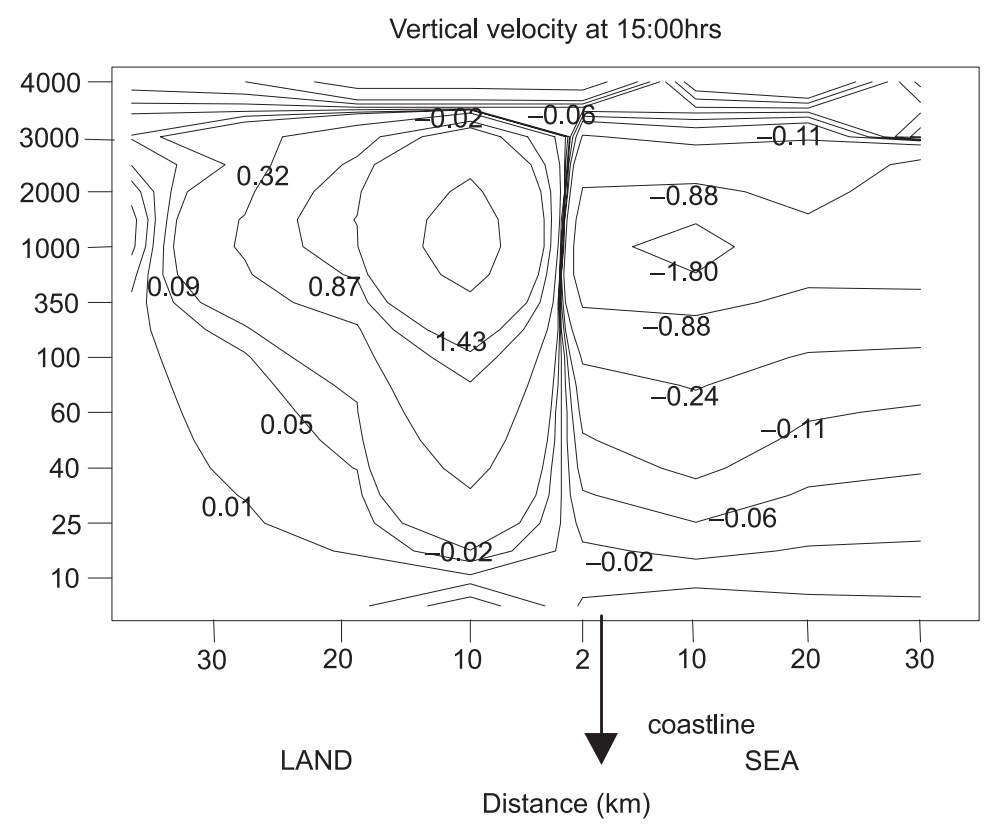

Figure 4. Spatial distribution of vertical velocity at sea breeze time.

6:00 hrs, winds are SSW at lower levels and westerly at higher levels. Thermal turbulence is gradually increased as the temperature of the land was enhanced due to the increase in solar radiation, thus developing low pressure over the land and high pressure over the sea.

In tropical regions like Kalpakkam, land-sea temperature difference will be high and thus cause developing of sea breeze. Winds are southwesterly until noon, and around 12:00 hrs, as the difference in land and sea temperatures is gradually increased to $3^{\circ} \mathrm{C}$ a weak offshore wind towards south easterly with increase in wind speed (not shown in the figure) is observed. In addition, at around 15:00 hrs when the temperature difference between land and sea reached $7^{\circ} \mathrm{C}$, southeasterly wind gradually penetrates towards inland simulating maximum strength of the sea breeze with increase in wind speed and decrease of temperature. This time of onset of sea breeze is exactly the same as that found in the kytoon observations. The strength of the sea breeze is increased gradually and reached a maximum at 18:00 hrs. Wind at 18:00 hrs up to 10 vertical levels $(z=100 \mathrm{~m})$ is also shown in close-up form in figure 3 to see the horizontal and vertical extent of the sea breeze. It is seen that the sea breeze is extended horizontally $40 \mathrm{~km}$ from the coast towards the land and $100 \mathrm{~m}$ vertically.

As solar radiation gets decreased, wind speed also decreases due to less difference between sea and land temperature. At around 23:00 hrs, we can see the wind moving towards sea simulating land breeze which is one hour delayed than that observed by field data. According to simulations, the strength of the sea breeze is from 15:00 hrs to 21:00 hrs. The spatial distribution of simulated vertical velocity at sea breeze time is shown in figure 4 and simulated maximum value is $1.43 \mathrm{~m} / \mathrm{sec}$.

\subsection{Spatial distribution, temporal variation and vertical profile of potential temperature}

The spatial distribution of simulated potential temperature is shown in figure 5 at $06: 00 \mathrm{hrs}$, 15:00 hrs, and 18:00 hrs. In the early hours of the day (say at 06:00 hrs), we can see a strong stable atmosphere over land and sea and the sea surface temperature is constant throughout the day. As temperature of the land increases there is an unstable atmosphere around 12:00 hrs (not shown in the figure) and after the onset of sea breeze around 15:00 hrs, there is a decrease in temperature over the land due to sea breeze indicating a stable atmosphere (as seen at 18:00 hrs). Temporal variation of potential temperature over land and sea is shown in figure 6 , which indicates the stable atmosphere over the land and unstable atmosphere over sea. The temperature over sea is seen constant up to $100 \mathrm{~m}$ height. The simulated potential temperature profile before and after the onset of the sea breeze is shown in figure 7 , where a decrease of $2^{\circ} \mathrm{C}$ in temperature is observed after onset of sea breeze. Potential temperature profiles before and after the onset of sea breeze are compared with the kytoon data collected in the field experiment and are shown in figure 8. It is found that the simulated temperature profiles are in good agreement with the field data. 

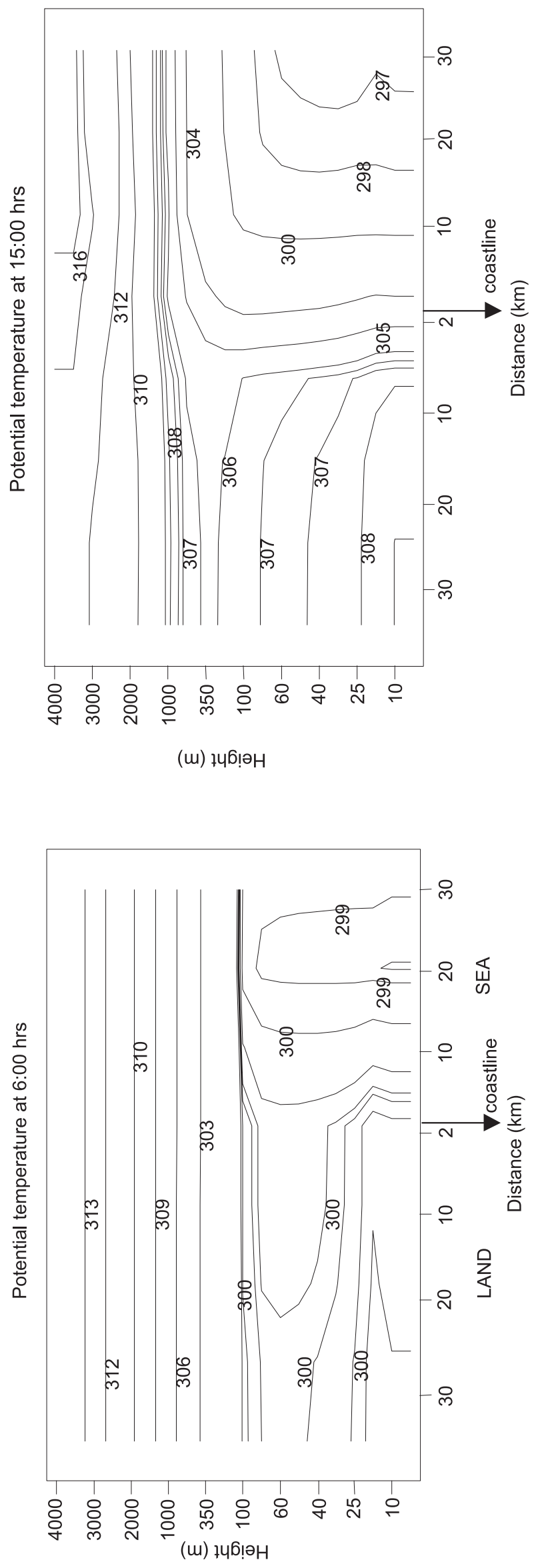

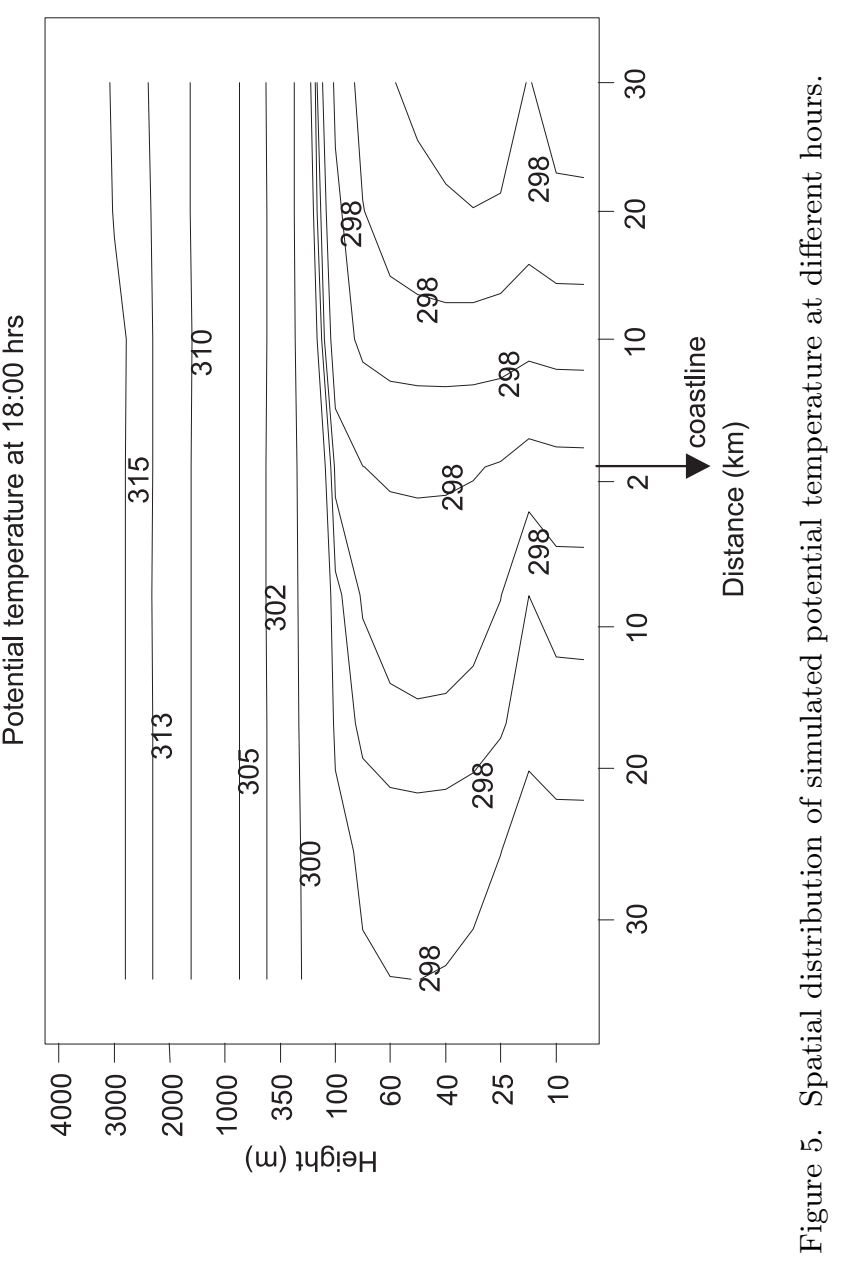



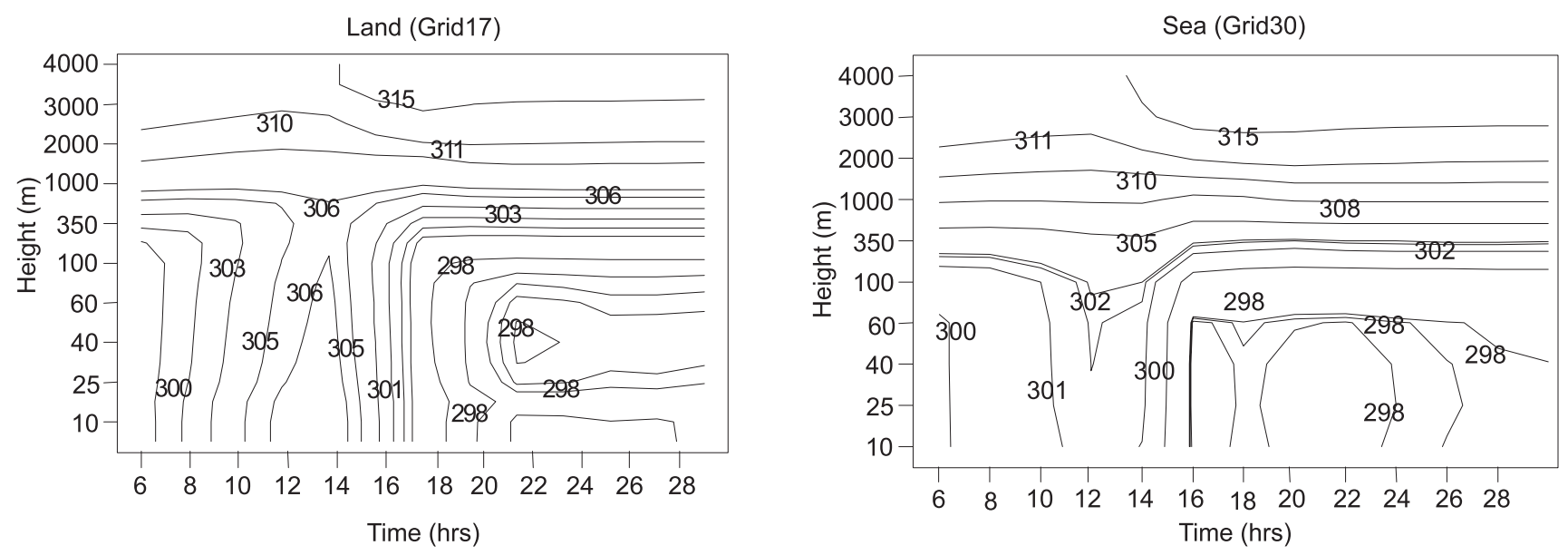

Figure 6. Temporal variation of potential temperature over land and sea.

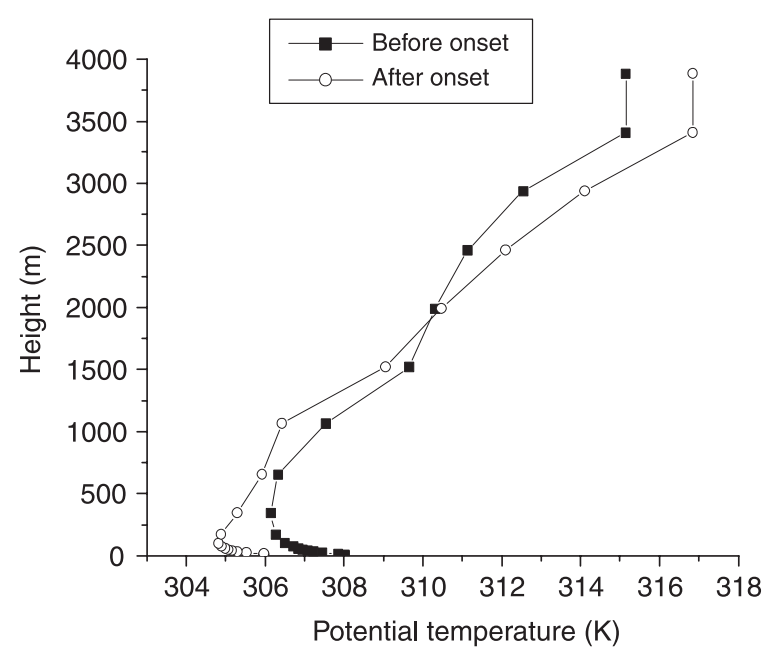

Figure 7. Simulated potential temperature profile before and after onset of sea breeze.

\subsection{TIBL height}

The formation and growth of Thermal Internal Boundary Layer (TIBL) due to change in roughness and temperature of the surface, plays an important role in understanding the diffusion properties of air pollutants. Melas and Kambezidis (1992) showed that TIBL depth is a function of downwind distance from the coastline, wind speed and land and sea surface roughness. The TIBL acts as a lid suppressing the vertical mixing of air pollutants. Hence, pollutants are entrapped within the TIBL. Growth of the TIBL is controlled by both convective and mechanical turbulence (Gryning and Batchvarova 1990). The height of the TIBL is simulated from potential temperature profiles where inversion is seen in the temperature profiles and it is observed as $238 \mathrm{~m}$ height above ground level with a downwind distance of $18 \mathrm{~km}$ from the coastline as shown in figure 9 .
It is also seen that there is an increase of TIBL depth with respect to distance from the coast. The height of the mixed layer above the TIBL is simulated as $1000 \mathrm{~m}$, where constant temperature is observed above the land as already shown in figure 5 .

\subsection{Comparison of model results with observed tower data}

Numerically predicted results are compared with the observed data collected in the field experiment. Wind profile simulated at 6:00 hrs is compared with the radiosonde data collected from IMD Chennai and is shown in figure 10, where a jet is seen to be simulated from the model as also observed in the data. Meteorological tower data collected near Anupuram, which is $5.5 \mathrm{~km}$ away from the coast, is used to compare the wind speed and wind direction simulated by the ARPS model. The tower data are collected at 10, 17, 29 and $50 \mathrm{~m}$ levels above the ground. Comparisons of wind speed and wind direction at respective levels are shown in figure 11. The results are in good agreement with the observed values from the field experiments. From the figure, we can see that the onset of sea breeze is simulated one hour before that observed according to the tower data. A sudden increase of wind speed from 4 to $9 \mathrm{~m} / \mathrm{sec}$ and a change in the direction of wind from southwesterly to southeasterly is seen when sea breeze was set at 15:00 hrs from the simulated values. A difference of 1 to $2 \mathrm{~m} / \mathrm{sec}$ wind speed is seen at all levels in the night time and for the rest of the day, wind speed is well simulated. Comparison of wind direction at 10,17,29 and $50 \mathrm{~m}$ is in good agreement with observed values during day time with the exception that wind direction at night and early hours of the next day, is not coinciding with 

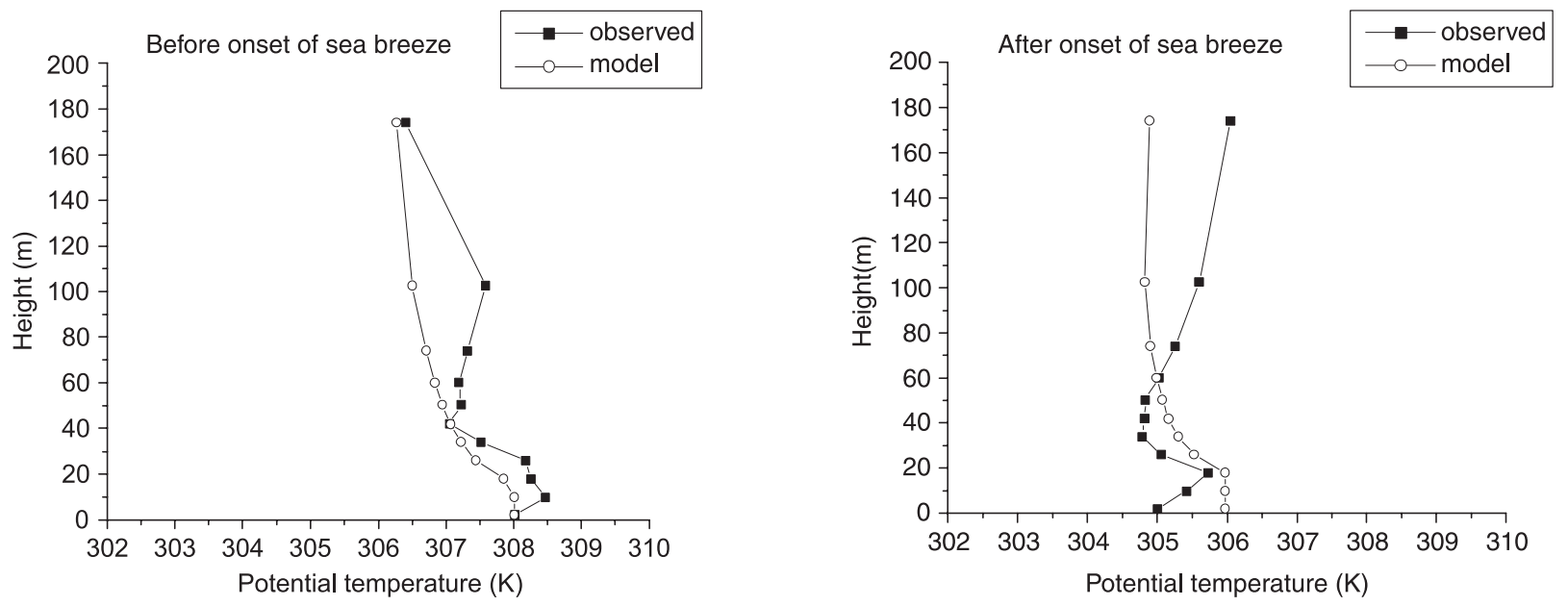

Figure 8. Comparison of potential temperature profiles with kytoon observations before and after the onset of sea breeze.

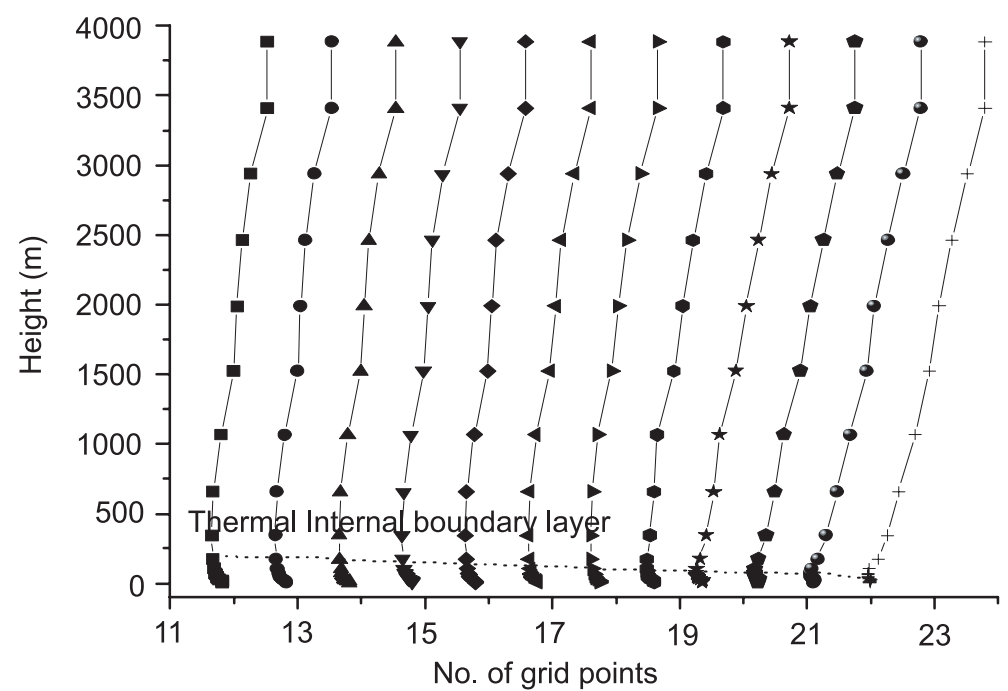

Figure 9. Profiles of potential temperature from grid 12 to grid 23. (Grid 21 is coast line) TIBL height is shown.

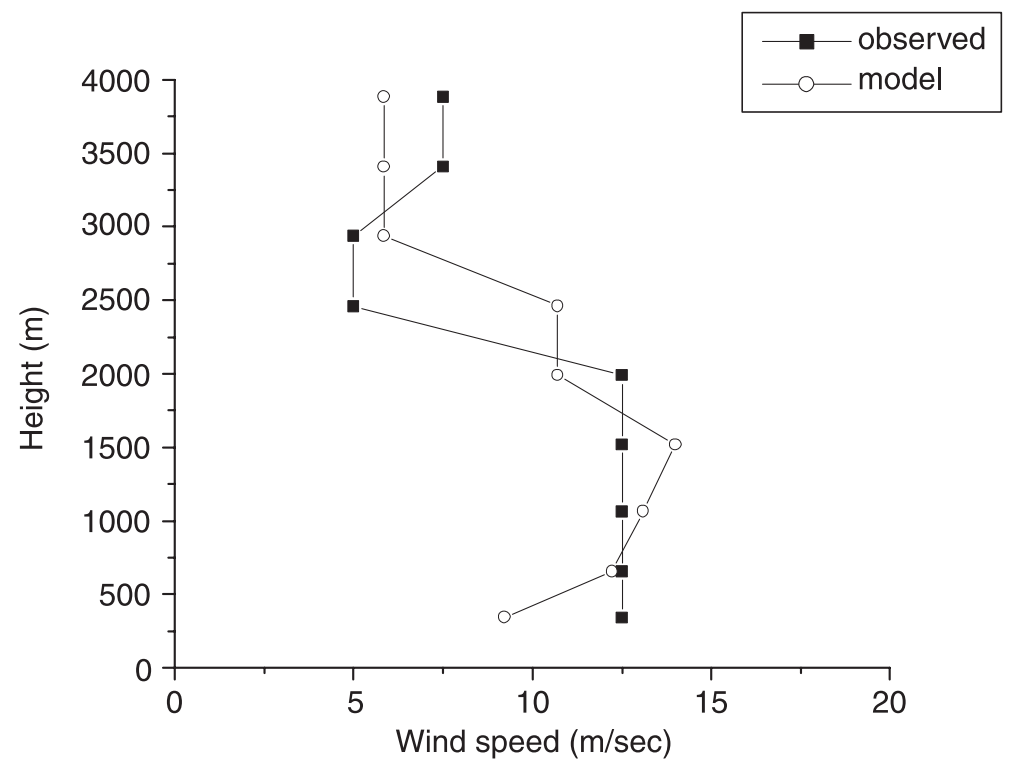

Figure 10. Comparison of wind profile at 6:00 hrs. 


the observed data. According to observations wind direction at $50 \mathrm{~m}$ is westerly until afternoon and moving SSE after 15:00 hrs. Nevertheless, by the simulated values, winds are southwesterly at morning hours and southeasterly after the onset of sea breeze. After 22:00 hrs we can see that winds moving from southeasterly to southwesterly simulating land breeze at all levels.

The simulated and observed values are shown in table 2. In earlier studies, most of the models have shown some discrepancies between the observed and simulated values. However, small discrepancies are observed in the present study because of the fact that the 1.5 TKE closure scheme used in the ARPS model is unable to predict the meteorological parameters realistically. The reason for this may be explained as the behavior of turbulent mixing will be different at the time of passage of the sea breeze front which is difficult to simulate in numerical models. For better simulations, it is suggested that large-eddy simulation models can be used.

Table 2. Comparison of experimentally observed values and numerically simulated values.

\begin{tabular}{l|l|l}
\hline & Numerical & Experimental \\
\hline $\begin{array}{l}\text { Maximum } \\
\text { temperature }\end{array}$ & $308 \mathrm{~K}$ & $309 \mathrm{~K}$ \\
$\begin{array}{l}\text { Minimum } \\
\text { temperature }\end{array}$ & $298 \mathrm{~K}$ & $300 \mathrm{~K}$ \\
$\begin{array}{l}\text { Sea breeze } \\
\text { onset time }\end{array}$ & $15-00$ hour & $16-00$ hour \\
$\begin{array}{l}\text { Sea breeze } \\
\text { strength }\end{array}$ & $8.3 \mathrm{~m} / \mathrm{sec}$ & $6.6 \mathrm{~m} / \mathrm{sec}$ \\
$\begin{array}{l}\text { Duration of } \\
\text { sea breeze }\end{array}$ & $15-00$ to $21-00$ & $16-00 \mathrm{to} 22-00$ \\
hours & $35 \%$ & $38 \%$ \\
Humidity & $658 \mathrm{~W} / \mathrm{m}^{2}$ & $506 \mathrm{~W} / \mathrm{m}^{2}$ \\
$\begin{array}{l}\text { Net } \\
\text { radiation }\end{array}$ & $77 \mathrm{~W} / \mathrm{m}^{2}$ & $122.48 \mathrm{~W} / \mathrm{m}^{2}$ \\
$\begin{array}{l}\text { Momentum } \\
\text { flux }\end{array}$ & $238 \mathrm{~W} / \mathrm{m}^{2}$ & $200 \mathrm{~W} / \mathrm{m}^{2}$ \\
$\begin{array}{l}\text { Sensible } \\
\text { heat flux } \\
\begin{array}{l}\text { TIBL height } \\
(5 \mathrm{~km} \text { inland } \\
\text { from coast) }\end{array}\end{array}$ & $87 \mathrm{~m}$ & $50 \mathrm{~m}$ \\
\hline
\end{tabular}

\section{Conclusions}

From the present investigations the following conclusions are observed:
- Sea breeze characteristics and thermal internal boundary layer structure in the coastal area around Kalpakkam was studied using ARPS mesoscale model in its two-dimensional form assuming the $y$ coordinate to be parallel to the coast.

- Strength and duration of sea breeze is simulated as $8.3 \mathrm{~m} / \mathrm{sec}$ and 6 hours respectively.

- Thermal internal boundary layer is simulated as $238 \mathrm{~m}$ height above the ground level and $18 \mathrm{~km}$ downwind distance from the coast.

- ARPS model results are compared with the observed data from the field experiment collected near Kalpakkam and simulated results are within acceptable limits.

- General trend in the meteorological parameters and coastal effects could be simulated by ARPS model. It is too optimistic to expect any model to simulate the exact atmospheric reality. Hence, ARPS model can be used to predict wind data for pollution dispersion models.

\section{Acknowledgement}

We would like to express our sincere thanks to the Director of IMD Nungambakkam for providing the synoptic data for the study. We also thank Dr. A R Sundarrajan, Associate Director, SR\&HPG and Dr. Natarajan, Head, Health and Safety Division, IGCAR, Kalpakkam and I.I.T. Madras for their continuous support to carry out this work.

\section{References}

Arrit W R 1987 The effect of water surface temperature on lake breezes and Thermal Internal Boundary Layers; Boundary Layer Meteor., 40 101-125

Batchvarova E and Gryning S E 1998 Wind climatology, atmospheric turbulence and internal boundary-layer development in Athens during the MEDCAPHOTTRACE experiment; Atmos. Environ., 32(12) 2055-2069

Bechtold P J, Pinty P and Mascart P 1991 A numerical investigation of the influence of large-scale winds on sea breeze and inland-breeze-type circulations; J. Appld. Met. 30 1268-1279

Cai X M and Steyn D G 2000 Modelling study of sea breezes in a complex coastal environment; Atmos. Environ., 34 $2873-2885$

Carissimo B, Dupont E and Marchand O 1996 Local simulations of land-sea breeze cycles in Athens based on large-scale operational analyses; Atmos. Environ. 30(15) 2691-2704

Estoque M A 1962 The sea breeze as a function of the prevailing synoptic situation; J. Atmos. Sci., 19 244-250

Gross G 1986 A numerical study of the land and sea breeze including cloud formation; Beitr. Phys. Atmosph. 59(1) 97-114

Gryning S E and Batchvarova E 1990 Analytical model for the growth of the coastal internal boundary during onshore flow; Q. J. R. Met. Soc. 116 187-203 
Jamima P, Venkatesan R and Aswatha Narayana P A 2001 An examination of the surface energy budget for various soil conditions and comparison with field data; Proceedings of TROPMET, 2001. 357-364

Klara F 1998 Inland and offshore propagation speeds of sea breeze from simulations and measurements; Boundary Layer. Meteor. 87 307-329

Liu H C, Johnny L, and Cheng A Y S 2001 Internal boundary layer structure under sea breeze conditions in Hong Kong; Atmos. Environ., 35 683-692

Ma J 1997 Numerial modeling of a sea breeze circulation over Cleveland Bay; Aust. Met. Mag. 46 1-13

Mahrer Y and Pielke R A 1977 The effects of topography on sea and land breezes in a two-dimensional numerical model; Mon. Weather Rev. 105 1151-1162

Melas D, Ziomas I C and Zerefos C S 1995 Boundary layer dynamics in an urban coastal environment under sea breeze conditions. Atmos. Environ. 29(24) 36053617

Melas D, Ziomas I C, Klemm O and Zerefos C S 1998a Flow dynamics in Athens area under moderate large-scale winds; Atmos. Environ. 32(12), 22092222

Melas D, Ziomas I C, Klemm O, and Zerefos C S, 1998b Anatomy of the sea breeze circulation in Athens area under weak large-scale ambient winds; Atmos. Environ. 32(12) 2223-2237

Melas D and Kambezidis H D 1992 The depth of the internal boundary layer over an urban area under sea breeze conditions; Boundary Layer. Meteor., $61247-$ 264

Neumann J and Mahrer Y 1971 A theoretical study of the land and sea breeze circulation; J. Atmos. Sci. 28532 542

Novitsky M, Reible D D and Corripio B M 1992 Modeling the dynamics of the land-sea breeze circulation for air quality modeling; Boundary Layer Meteor. 59 163175

Ogawa Y, Ohara T, Wakamatsu S, Diosey P G and Uno I 1986 Observation of lake breeze penetration and subsequent development of the thermal internal boundary layer for the NANTICOKE II shoreline diffusion experiment; Boundary Layer Meteor. 35 207-230
Osamu C, Naito G, Kobayashi F and Toritani H 1994 Wave trains over the sea due to sea breezes; Boundary Layer Meteor. 70 329-340

Simpson J E 1995 Sea breeze and local winds. (Cambridge University Press) 234pp

Sivaramakrishnan S and Venkatesan R 2002 Coastal Atmospheric Boundary Layer Experiment (CABLE)2001, A Report submitted to AERB, Mumbai, India.

Thara V P, Anandakumar K, Venkatesan R and Somayaji K M 2000 Coastal Atmospheric Boundary Layer Experiment (CABLE - 98); IGC-213 Report on site specific parameters. Health and Safety Division, IGCAR, Kalpakkam. (Available from L\&IS, IGCAR, Kalpakkam, 603 102, India)

Thara V P, Venkatesan R and Sitaraman V 1999 Simulation of meteorological fields over a land-water-land terrain and comparison with observations; Boundary Layer Meteor. $91227-257$

Thara V P, Venkatesan R, Mursch-Radlgruber E, Rengarajan G and Jayanthi N 2002 Thermal Internal Boundary Layer characteristics at a tropical coastal site as observed by a mini-SODAR under varying synoptic conditions; Proc. Indian Acad. Sci. (Earth Planet. Sci.) 111(1) 6377

Xian Z and Pielke R A 1991 The efeects of width of landmasses on the development of sea breezes; J. Appld. Meteor., 30(9) 1280-1304

Xue M, Droegemeier K K, Wong V, Shapiro A and Brewster K 1995 ARPS Version 4.0 User's Guide.

Xue M, Droegemeier K K and Wong V 2000 The Advanced Regional Prediction System (ARPS) - A multiscale nonhydrostatic atmospheric simulation and prediction tool. Part I: Model dynamics and verification; Meteor. Atmos. Physics. 75 161-193

Xue M, Droegemeier K K, Wong V, Shapiro A, Brewster K, Carr F, Weber D, Liu Y and Wang D H 2001 The Advanced Regional Prediction System (ARPS) - A multiscale nonhydrostatic atmospheric simulation and prediction tool. Part II: Model physics and applications; Meteor. Atmos. Physics. 76 134-165

Zambakas J D 1973 The diurnal variability and duration of the sea breeze at the National Observatory of Athens, Greece; Meteorology Magazine 102 222-228 